\title{
PERBEDAAN KELENGKAPAN REKAM MEDIS RAWAT JALAN PUSKESMAS TERAKREDITASI UTAMA DAN MADYA KABUPATEN SUKOHARJO
}

\author{
Astri Sri Wariyanti ${ }^{1}$, Harjanti ${ }^{2}$ \\ ${ }^{1}$ Prodi Sarjana Terapan Manajemen Informasi Kesehatan STIKes Mitra Husada Karanganyar \\ ${ }^{2}$ Prodi D3 Rekam Medis STIKes Mitra Husada Karanganyar \\ Email: ${ }^{1}$ astrimhk@gmail.com, ${ }^{2}$ harjantimhk@ gmail.com
}

\begin{abstract}
ABTRACT
Preliminary survey results reveal that there are differences in completeness at the Main and Middle Accredited Health Centers in the District Health Office of Sukoharjo Regency. The results of completeness in the Primary accredited Puskesmas reach 80\%, while in the Middle accreditation 73\%. The purpose of this study was to determine the differences in the completeness of outpatient medical records in primary and intermediate accredited health centers in Sukoharjo Regency. Research Methods. This type of research is Analytical Observational research. The study was conducted in June-July 2019. The population was all outpatient medical record documents in 2018. The sample used purposive sampling, 120 outpatient medical record documents were taken. The research instrument uses a checklist and observation guidelines. How to collect data by observing outpatient medical record documents and interviews. Quantitative data analysis with the Man Whitney Test. Results of research The average completeness of medical record documents showed that primary health centers with higher accreditation were higher than mid-accredited puskesmas with a value of $77.07 \%$ and $75.2 \%$, and the difference in completeness of medical record documents with primary accreditation with intermediate accreditation with $p=0.001$. It is recommended that socialization be carried out to all officers who fill out medical records, especially doctors so that the completeness of authentication and all items of completeness can increase or reach $100 \%$.
\end{abstract}

Keyword : Completeness, Accreditation Status, Main, Intermediate

\begin{abstract}
ABSTRAK
Hasil survei awal diketahui bahwa terdapat perbedaan kelengkapan pada Puskesmas Terakreditasi Utama dan Madya di Wilayah Dinas Kesehatan Kabupaten Sukoharjo. Hasil kelengkapan di Puskesmas terakreditasi Utama mencapai 80\%, sedangkan pada akreditasi Madya 73\%. Tujuan penelitian ini untuk mengetahui perbedaan kelengkapan rekam medis rawat jalan di puskesmas terakreditasi utama dan madya di Kabupaten Sukoharjo. Metode Penelitian, Jenis penelitian ini adalah penelitian Observasional Analitik. Penelitian dilaksanakan pada bulan Juni-Juli 2019. Populasi adalah seluruh dokumen rekam medis rawat jalan tahun 2018. Sampel menggunakan purposive sampling, diambil 120 dokumen rekam medis rawat jalan. Instrumen penelitian menggunakan checklist dan pedoman observasi. Cara pengumpulan data dengan observasi dokumen rekam medis rawat jalan dan wawancara. Analisis data dengan kuantitatif dengan uji Man Whitney Test. Hasil penelitian Rata-rata kelengkapan dokumen rekam medis menunjukkan puskesmas dengan akreditasi utama lebih tinggi daripada puskesmas terakreditasi madya dengan nilai $77,07 \%$ dan $75,2 \%$, serta danya perbedaan kelengkapan dokumen rekam medis puskesmas akreditasi utama dengan akreditasi madya dengan nilai $\mathrm{p}=0,001$. Disarankan agar dilaksanakannya sosialisasi kepada semua petugas yang mengisi rekam medis, terutama dokter agar kelengkapan autentikasi dan semua item kelengkapan dapat meningkat atau mencapai $100 \%$.
\end{abstract}

Kata Kunci : Kelengkapan, Status Akreditasi, Utama, Madya 


\section{PENDAHULUAN}

Mutu pelayanan kesehatan adalah derajat kesempurnaan pelayanan kesehatan yang sesuai standar profesi dan standar pelayanan dengan menggunakan potensi sumber daya yang tersedia di rumah sakit atau puskesmas secara wajar, efektif dan efisien. Mutu pelayanan kesehatan menjadi hal penting dalam organisasi pelayanan kesehatan karena mendorong puskesmas untuk sadar mutu dalam memberikan pelayanan yang lebih baik. Semakin pasien puas, maka semakin baik pula mutu pelayanan kesehatan (Herlambang, 2016).

Salah satu pelayanan kesehatan yang terkait adalah Puskesmas, yaitu fasilitas pelayanan kesehatan untuk meningkatkan derajat kesehatan. Hal yang dapat dilaksanakan adalah pelayaan rekam medis. (Permenkes RI 46, 2015). Rekam medis adalah suatu catatan yang berisikan riwayat keadaan pasien dari awal sampai akhir (Sudra, 2013). Hal penting dalam pencatatan rekam medis adalah kelengkapannya.

Kelengkapan rekam medis yang prosesnya disebut analsis kuantitatif adalah suatu telaah bagian tertentu dalam rekam medis untuk bermaksud mengetahui kekurangaan dalam pencatatan pada formulir rekam medis, menjamin efektivitas kegunaan isi rekam medis di kemudian hari. Selain itu juga untuk mengidentifikasi bagian yang tidak lengkap sehingga mudah dikoreksi sesuai prosedur yang berlaku. Analisis kuantitatif terdapat 4 review, yaitu review identifikasi, laporan penting, autentikasi, serta teknik pencatatan. (Sudra, 2013).

Jika kelengkapan rekam medis puskesmas dapat tercapai maka akan meningkatkan mutu rumah sakit apalagi untuk tujuan akreditasi. Sesuai Permenkes RI (2015) tentang akreditasi, salah satu elemen yang yang harus dicapai adalah kelengkapan pengisian rekam medis sehingga jika Puskesmas telah terakreditasi maka diharapkan semakin baik pula kelengkapan dokumen rekam medisnya.

Tetapi kenyataannya masih banyak dijumpai ketidaklengkapan pengisian dokumen rekam medis. Hal ini menjadi salah satu masalah karena rekam medis tidak dapat memberikan informasi terinci tentang apa yang terjadi selama pasien berada di puskesmas. Winarti (2013) menyebutkan bahwa kelengkapan dokumen rekam medis menunjukkan presentase $85 \%$ karena ketidakpatuhan petugas dan belum sepenuhnya menyadari tentang pentingnya rekam medis, selain itu belum adanya pendampingan setelah dilaksanakannya akreditasi, sehingga dari temuan ketidaklengkapan yang ditemukan tidak dikaji ulang, serta tidak didukung dari upaya rumah sakit itu sendiri.

Hasil survei awal diketahui bahwa terdapat perbedaan kelengkapan pada Puskesmas Terakreditasi Utama dan Madya di Wilayah Dinas Kesehatan Kabupaten Sukoharjo. Hasil kelengkapan di Puskesmas terakreditasi Utama mencapai $80 \%$, sedangkan 
pada akreditasi Madya $73 \%$.

Ketidaklengkapan ini dikarenakan pada penulisan nama dokter serta teknik pencatatan banyak petugas yang tidak mengisi garis tetap yaitu tanda jika item dalam formulir rekam medis tidak diisi.

Tujuan penelitian ini untuk mengetahui perbedaan kelengkapan rekam medis rawat jalan di puskesmas terakreditasi utama dan madya di Kabupaten Sukoharjo.

\section{METODE PENELITIAN}

Jenis penelitian ini adalah penelitian Observasional Analitik. Penelitian dilaksanakan pada bulan Juni-Juli 2019. Lokasi penelitian dilaksanakan di Puskesmas Sukoharjo, Puskesmas Grogol, Puskesmas Bendosari, dan Puskesmas Polokarto Kabupaten Sukoharjo. Populasi adalah seluruh dokumen rekam medis rawat jalan tahun 2018. Sampel menggunakan purposive sampling, diambil 120 dokumen rekam medis rawat jalan. Variabel terikat dalam penelitian ini adalah kelengkapan pengisian identitas pasien, laporan penting, autentikasi, dan pendokumentasian yang benar dan sebagai variabel bebas adalah status akreditasi yaitu Utama dan Madya. Instrumen penelitian menggunakan checklist dan pedoman observasi. Cara pengumpulan data dengan observasi dokumen rekam medis rawat jalan dan wawancara kepada penanggungjawab rekam medis untuk menggali faktor ketidaklengkapan. Analisis data dengan kuantitatif dengan uji Man Whitney Test untuk mengetahui pperbedaan kelengkapan dokumen rekam medis dengan Akreditasi Utama dan Madya di Wilayah Kabupaten Sukoharjo.

\section{HASIL PENELITIAN}

A. Rata-rata Kelengkapan Dokumen Rekam Medis Puskesmas Terakreditasi Utama dan Madya

Tabel 1. Rata-rata kelengkapan dokumen

\begin{tabular}{|c|c|c|c|}
\hline No & $\begin{array}{c}\text { Review } \\
\text { Kelengkapan }\end{array}$ & $\begin{array}{c}\text { Akreditasi } \\
\text { Utama } \\
\mathrm{N}(\%)\end{array}$ & $\begin{array}{c}\text { Akreditasi } \\
\text { Madya } \\
\text { N (\%) }\end{array}$ \\
\hline 1. & $\begin{array}{c}\text { Identifikasi } \\
\text { (Nomor RM, } \\
\text { Nama, Tgl } \\
\text { Lahir/Umur) }\end{array}$ & 99 & 100 \\
\hline 2. & $\begin{array}{c}\text { Laporan } \\
\text { Penting } \\
\text { (Tanggal } \\
\text { Periksa, } \\
\text { Anamnesis, } \\
\text { Pemeriksaan } \\
\text { Fisik, } \\
\text { Diagnosis, } \\
\text { Pengobatan) }\end{array}$ & 91,6 & 94,9 \\
\hline 3. & $\begin{array}{c}\text { Autentikasi } \\
\text { (Nama dokter, } \\
\text { tanda tangan } \\
\text { dokter/ } \\
\text { perawat) }\end{array}$ & 53,5 & 43,2 \\
\hline 4. & $\begin{array}{c}\text { Tehnik } \\
\text { Pencatatan } \\
\text { (Penulisan } \\
\text { Jelas Terbaca, } \\
\text { Pembetulan } \\
\text { Kesalahan, } \\
\text { Garis Tetap) }\end{array}$ & 64,2 & 64,8 \\
\hline & $\begin{array}{l}\text { Rata-rata } \\
\text { Kelengkapan }\end{array}$ & 77,07 & 75,72 \\
\hline
\end{tabular}


Berdasarkan tabel 1 diketahui rata-rata kelengkapan Puskesmas terakreditasi Utama 77,07\%, sedangkan Madya 75,01. Disini dapat diketahui Puskesmas yang terakreditasu Utama lebih tinggi kelengkapannya daripada Puskesmas yang terakreditas Madya.

B. Uji Hipotesis Perbedaan Kelengkapan Pengisian Dokumen Rekam Medis Puskesmas Terakreditasi Utama dan Madya

Tabel 2 Uji Hipotesis (Mann Whitney Test)

\begin{tabular}{lllll}
\hline & $\begin{array}{l}\text { Status } \\
\text { Akreditasi }\end{array}$ & N & $\begin{array}{l}\text { Mean } \\
\text { Rank }\end{array}$ & p \\
\hline Kelen & Madya & 240 & 201,2 & 0.0 \\
gkapa & & & 1 & 01 \\
n & Utama & 240 & 279,7 & \\
& Total & 480 & 9 & \\
\hline
\end{tabular}

Berdasarkan tabel 2 diketahui hasil uji statistik Mann Whitney Test dengan nilai $\mathrm{p}=0,001$.

\section{PEMBAHASAN}

Puskesmas Bendosari dan Puskesmas Polokarto merupakan puskesmas di wilayah dinas kesehatan kabupaten Sukoharjo dengan akreditasi Utama, sedangkan Puskesmas Sukoharjo dan Puskesmas Grogol merupakan puskesmas di wilayah dinas kesehatan kabupaten Sukoharjo dengan akreditasi Madya. Dari hasil penelitian diketahui ratarata kelengkapan di Puskesmas terakreditasi Utama adalah 77,07 dan Puskesmas Terakreditasi Madya 75,01.
Review kelengkapan tertinggi terdapat pada review identifikasi dengan angka 99\% dan $100 \%$, Hal ini disebabkan karena petugas pendaftaran telah disiplin dalam penulisan identitas pasien setelah pelaksanaan akreditasi, serta dilaksanakan sosialisasi di puskesmas tentang kelengkapan dokumen rekam medis.

Hal ini sesuai dengan Vehedi (2018) Kelengkapan dokumen rekam medis mencapai $100 \%$ dikarenakan semua petugas mengikuti workshop dan sosialisasi tentang rekam medis. Selaras dengan Sudra bahwa kelengkapan identifikasi pasien pada setiap formulir rekam medis wajib mencantumkan identitas pasien dengan lengkap sehingga memudahkan dalam proses pemberian pelayanan kesehatan kepada pasien.

Secara umum pelaksanaan identifikasi sudah berjalan baik di kedua puskesmas, namun masih ditemukan pengisian rekam medis yang belum lengkap di Puskesmas Bendosari. Berdasarkan hasil wawancara, petugas rekam medis tidak sempat menulis identitas pasien dikarenkaan pasien yang mendaftar banyak, biasanya dokter/perawat yang mengisi pada saat pengobatan, tetapi juga tidak dilakukan. di puskesmas bendosari ini pencatatan identitas masih dilaksanakan manual, belum ada label sehingga terjadi ketidaklengkapan tersebut. Hal ini belum sesuai Permenkes RI (2008) bahwa salah satu data minimal yang harus ada pada formulir rekam medis adalah identitas pasien untuk mengetahui kepemilikan formulir. Keterisian identitas pasien dapat meminimalisir 
terjadinya kesalahan diagnosis atau pemberian obat/tindakan kepada pasien.

Review kelengkapan terendah pada item autentikasi yang berisi nama dan tanda tangan dokter/ perawat dengan nilai $53,5 \%$ dan 43,2\%. Hal ini terjadi dikarenakan pada formulir rawat jalan hanya tertulis ttd petugas, sehingga petugas penanggungjawab tidak mengisi nama. Selain itu tingkat kesadaran juga masih rendah, hal ini dibuktikan dengan ketidaklengkapan masih tinggi. Petugas hanya mengisi keluhan dan pengobatannya saja karena pasien banyak sehingga tidak mengisi nama/tanda tangan. Tidak lengkapnya stempel nama dokter juga berpengaruh terhadap kelengkapan ini akan mempercepat pekerjaan.

Sejalan dengan Nurliani (2017) dan Murni (2019) bahwa ketidaklengkapan item tandatangan Kurang dari $60 \%$ dikarenakan kesibukan dokter untuk mengisi sehingga dokter hanya mengisi tanda tangan saja. Selaras dengan Hatta (2013) Rekam medis juga menyatakan bahwa setiap pencatatan yang ditulis dalam rekam medis harus dibubuhi nama, dan tandatangan dokter atau tenaga kesehatan lain yang memberikan pelayanan kesehatan secara langsung, sehingga informasi rekam medis dapat menjadi alat pertanggungjawaban yang berlandaskan hukum.

Secara umum rata-rata kelengkapan sudah mencapai $75 \%$ dimana puskesmas akreditasi utama lebih tinggi kelengkapannya daripada puskesmas dengan akreditasi madya. Sejalan dengan Devkaran (2014) yang menyatakan bahwa status nilai akreditasi dan kinerja memiliki keeratan hubungan kuat atau tinggi, maka semakin baik status nilai akreditasi, maka semakin tinggi pula kinerjanya sehingga meningkatkan mutu rekam medis di puskesmas. Mutu rekam medis puskesmas dapat dicapai jika petugas yang mengisi rekam medis patuh dalam mengisi setiap formulir rekam medis pasien. Tetapi kelengkapan ini belum sesuai Standar Pelayanan Minimal di Fasilitas Pelayanan Kesehatan No 129 Th 2008 bahwa kelengkapan pengisian dokumen rekam medis harus $100 \%$ lengkap.

Uji perbedaan menggunakan Uji Man Whitney Test karena distribusi tidak normal. Rata - rata peringkat kelengkapan tiap kelompok (status akreditasi) yaitu kelompok puskesmas terakreditasi madya rerata peringkat kelengkapannya adalah 201,21 lebih rendah daripada rerata puskesmas terakreditasi utama, yaitu 279,79. Nilai sig atau p-value $=0.001 \quad(<0.05)$ yang berarti terdapat perbedaan kelengkapan dokumen rekam medis yang bermakna antara kelompok puskesmas madya dan utama.

Pelaksanaan akreditasi dapat memberikan kontribusi yang positif terhadap peningkatan mutu, maka dapat artikan bahwa semakin baik status nilai akreditasi, maka semakin tinggi pula kualitas atau mutu pelayanan termasuk mutu rekam medis yang dimiliki oleh puskesmas (Beaudry, 2017). 


\section{SIMPULAN}

1. Rata-rata kelengkapan dokumen rekam medis menunjukkan puskesmas dengan akreditasi utama lebih tinggi daripada puskesmas terakreditasi madya dengan nilai $77,07 \%$ dan $75,2 \%$

2. Adanya perbedaan kelengkapan dokumen rekam medis puskesmas akreditasi utama dengan akreditasi madya dengan nilai $\mathrm{p}=0,001$.

\section{SARAN}

1. Disarankan agar dilaksanakannya sosialisasi kepada semua petugas yang mengisi rekam medis, terutama dokter agar kelengkapan autentikasi dan semua item kelengkapan dapat meningkat atau mencapai $100 \%$.

2. Disarankan untuk membuat label identitas sehingga petugas langsung bisa print dan mengurangi angka ketidaklengkapan.

\section{DAFTAR PUSTAKA}

1. Beaudry, M. L., Bialek, R., 2014. Using Quality Improvement Tools and Methods Throughout the accreditation lifecycle. Journal Public Health Management Practice 2014, 20(1), 49-51

2. Departemen Kesehatan Republik Indonesia. (2008). Peraturan Menteri Kesehatan Republik Indonesia No. 269/ MENKES/ III/ 2008 tentang Rekam Medis. Jakarta: Depkes RI
3. Departemen Kes RI. 2008. Keputusan Menteri Kesehatan RI No 129/MENKES/SK/II/2008 tentang Standar Pelayanan Minimal Rumah Sakit. Jakarta: Dirjenyanmed.

4. Devkaran,S., Farrel, PN. 2014. The Impact of Hospital Accreditation on Clinical Documentation Compliance : A Life Cycle Explanation Using Interrupted Time Series Analysis. British Medical Journal Vol. 4. e005240

5. Hatta,GR. Ed. 2013. Pedoman Manajemen Informasi Kesehatan. Edisi Revisi. Jakarta: Indonesia Universitas.

6. Herlambang S. (2016). Manajemen Pelayanan Kesehatan Rumah Sakit. Gosyeng Publishing. Yogyakarta.

7. Murni T, Suhartina I, Dwi I. 2019. Analisis Kuantitatif Ketidaklengkapan Pengisian Resume Medis berdasarkan Program Quality Assurance. Jurnal Kesehatan Vokasional Indonesia. Volume 4(2) Mei 2019. ISSN 2599-3275. DOI h_ps://doi.org/10.22146/jkesvo.43948

8. Nurliani A. 2017. Analisis Kuantitatif Kelengkapan Dokumen Rekam Medis Rawat Inap Formulir Ringkasan Masuk dan Keluar. Jurnal STIKes Persada Husada Indonesia. Vol 4(12). Jakarta

9. Sudra, RI. 2013. Rekam Medis Edisi Kedua. Tangerang Selatan: Penerbit Universitas Terbuka

10. Vehedi HS, et al. 2018. Impact of an educational intervention on medical records documentation. World Journal of 
Emergency Medicine 2018; 9(2): 136-140.

doi: $\underline{10.5847 / \text { wjem.j. } 1920-}$

$\underline{8642.2018 .02 .009}$ diakses melalui

https://www.ncbi.nlm.nih.gov/pmc/articles/

PMC5847500/ tanggal 24 Agustus 2019.

11. Wirajaya MKM. (2019). Faktor yang mempengaruhi Ketidaklengkapan Rekam Medis Pasien pada Rumah Sakit di Indonesia. Jurnal Manajemen Informasi Keehatan Indonesia. Vol 7 (2). Oktober 2019. ISSN 2337-6007.

12. Winarti, Supriyanto S. 2013. Analisis Kelengkapan Pengisian dan Pengembalian Rekam Medis Rawat Inap di Rumah Sakit. Jurnal Administrasi Kesehatan Indonesia Vol 1 (4), Sept-Des 2013. 